Sharif University of Technology
Scientia Iranica
SCIENTIA
I RAN I C A

\title{
The effects of drivers' behavior on driver-injury severities in Iran: An application of the mixed-logit model
}

\author{
A. Behnood*, M. Modiri-Gharehveran and A.M. Roshandeh \\ Lyles School of Civil Engineering, Purdue University, 550 Stadium Mall, West Lafayette, IN 47907-2051, USA.
}

Received 14 January 2014; received in revised form 29 July 2015; accepted 12 October 2015

\author{
KEYWORDS \\ Driver-injury severity; \\ Mixed logit model; \\ Unobserved \\ heterogeneity; \\ Unsafe driving; \\ Interprovincial routes.
}

\begin{abstract}
It has long been established that adverse drivers' behaviors, including behavior relating to distracted driving, propensities for risk-taking, and disregard for traffic rules, have been critical determinants with regard to the likelihood of a vehicle crash and its resulting injury severity. Socio-economic/educational/cultural factors have significant positive effects on traffic-related fatalities. Using crash data from Iran over a six-year period from January 1, 2006 to December 31, 2011, this paper estimates a mixed logit model to investigate the unsafe driving behavior effects on driver-injury severities in a vehicle collision on interprovincial routes. The methodological approach allows the parameters to vary across observations as opposed to a fixed parameter model. The results showed random effects of female drivers, separated bi-directional route and clear weather condition for no injury severity function, following too closely for minor injury function, and average annual daily traffic for severe injury function. Several factors were found to significantly increase the likelihood of severe injury crashes including disregarding traffic rules, exceeding the speed limit, improper overtaking/passing, and driving in an erratic and negligent manner. The results of this paper will further help decision-makers to better understand the contributing factors on crash injury severity and implement treatments to reduce the crash severity and improve transportation safety.
\end{abstract}

(C) 2016 Sharif University of Technology. All rights reserved.

\section{Introduction}

Road traffic injury and fatality is serious but often neglected public health problem. Recent data shows that in 2012, road traffic injuries are the leading cause of death for young people aged 15-29 [1]. In Iran, a large number of vehicles are involved in road traffic accidents each year, causing high number of

\footnotetext{
*. Corresponding author. Tel.: +1(312)-647-8351;

Fax: +1(765)-494-1364

E-mail addresses: abehnood@purdue.edu (A. Behnood);

mmodirig@purdue.edu (M. Modiri-Gharehveran);

aroshand@purdue.edu (A.M.Roshandeh)
}

traffic-related fatalities and injuries. Although published data in 2013 show a decreasing trend started in 2006, Iran has one of the highest fatality rates of road traffic crashes across the globe (i.e., 34.1 per 100,000 population in Iran compared with 18 per 100,000 worldwide and 21.3 per 100,000 in the Eastern Mediterranean Regions) [2,3]. There are many possible reasons for this high incidence of traffic-related death, including poor infrastructure for public transportation, increasing number of cars and motorcycles that would not meet safety standards elsewhere, and poor education of people about traffic rules. Socioeconomic/educational/cultural factors (e.g., social willingness to comply with the law) have significant pos- 
itive effects on traffic-related fatalities [4-6]. Drivers with higher levels of education have been found to be associated with less severe crashes [7]. It has also been reported that safe driving behaviors are rational and mature habits that are shaped in response to exposure to relevant information and norms. Therefore, it is expected that safe driving habits to be affected by education and income [8]. Despite the tangible heterogeneity among the road users due to regional and socio-cultural differences, traffic rules in Iran are the same all across the country (i.e., province/regionalwide traffic rules are not legislated in Iran). This fact might be another possible contributing factor to high fatality rate of road crashes.

The main objective of this study is to analyze the effects of the safe driving behavior on driverinjury severities in single-vehicle crashes that occur on interprovincial roads. Therefore, in the current study, we are interested in specifically studying the effects of unsafe driving behavior on driver-injury severities. In addition, a wide range of other factors such as gender, age, time of day, weather conditions, roadway characteristics, etc. are controlled. A mixed logit model is applied to consider the possibility of heterogeneous mean for the random parameter distributions. Random parameters in crash-severity analysis account for the effect of unobserved factors across crash observations. Random parameters improve the overall fit of the model and the significance of the other parameters. In addition, these parameters can lead to effective policy decisions under different conditions. For example, random parameters allow decision makers to find different classes of observations and apply different scenarios for different conditions (e.g., different locations) [9].

The results of this study will help to understand the relationship between the injury severity of drivers and various contributing factors such as educational factors, time and weather characteristics, and roadway conditions. Such information will further help decisionmakers better understand the contributing factors on crash injury severity and implement treatments to reduce the crash severity and improve transportation safety.

\section{Methodology}

Many studies have been done to analyze and model the accident-injury severities using a wide variety of methodological approaches such as multinomial logit models, dual-state multinomial logit models, nested logit models, ordered probit models, and mixed logit models [10-23]. Furthermore, data mining techniques like classification and regression tree (CART) models [24], Artificial Neural Networks (ANN) [25,26], and Support Vector Machine (SVM) [27] can also be used to study the crash severity. A comprehensive literature review of crash-injury severity models and approaches was done by Savolainen et al. [28].

The ordered logit and probit models can only find one coefficient for each variable. The estimated coefficient is in one direction, either towards higher or lower severities. Although it is possible to use random parameters, but being constraint is inherent for ordering. Probably, the most common approach to statistically analyzing the injury severity is to use a discrete model. The multinomial logit model relaxes the ordinal constraint on the effect of variables. However, multinomial logit (MNL) model as one of the most widely preferred models in injury severity analysis maintains strict assumptions on the unobserved error terms in the model [29]. The main assumption associated with MNL is that the unobserved error terms must be independently and identically distributed [30]. This assumption will be violated if the unobserved error terms are heteroskedastic or correlated.

Mixed logit model, also referred to as mixed multinomial logit model, the error-components logit model, and the random parameters logit model, is highly flexible model that can be used to approximate different random utility functions [31,32]. Mixed logit model accounts for the limitations of standard multinomial logit model by allowing for random variation across the observations and unrestricted substation patterns. In addition, the model can allow for correlation in unobserved error terms from one injuryseverity level to the next. Such a correlation causes a violation of the model's Independence of Irrelevant Alternatives (IIA) property [33]. By using mixed logit model, some of the parameters are held fixed, while some others are allowed to be random. This model is very effective in studying the behavior of the populations with significant heterogeneity. Due to cultural, educational, and regional factors, it is expected to experience significant heterogeneity among the drivers in a wide country such as Iran where no regional traffic rules are legislated. The importance of using random parameter has been studied in previous researches [20-22,28,34].

In this study, random parameters (mixed) logit model is applied to investigate the driver-injury severities (with possible outcomes of severe injury, minor injury, and no injury). To develop the modeling approach, a severity function determining the injury severities is defined as [28]:

$$
S_{\text {in }}=\boldsymbol{\beta}_{i} \mathbf{X}_{\mathrm{in}}+\varepsilon_{\mathrm{in}}
$$

where $S_{\text {in }}$ is a severity function determining the injuryseverity category, $\boldsymbol{\beta}_{i}$ is a vector of estimable parameters for discrete outcome $i, \mathbf{X}_{\mathrm{in}}$ is a vector of the observable characteristics that impacts the injury severity for observation $n$, and $\varepsilon_{\text {in }}$ is a disturbance or error term. If the disturbances are extreme value, the standard 
multinomial logit model results such that [30]:

$$
P_{n}(i)=\frac{\exp \left[\boldsymbol{\beta}_{i} \mathbf{X}_{\mathrm{in}}\right]}{\sum_{I} \exp \left(\boldsymbol{\beta}_{i} \mathbf{X}_{\mathrm{in}}\right)}
$$

where $\operatorname{Pn}(i)$ is the probability of observation $n$ having discrete outcome $i$ ( $i \in I$, with $I$ denoting all possible outcomes for observation $n$ ). The outcome probabilities of a mixed model (a model with a mixing distribution), which allows for parameter variation, are defined as:

$$
P_{\mathrm{in}}^{m}=\int P_{n}(i) f(\boldsymbol{\beta} \mid \boldsymbol{\varphi}) d \boldsymbol{\beta},
$$

where $f(\boldsymbol{\beta} \mid \boldsymbol{\varphi})$ is the density function of $\boldsymbol{\beta}$ with $\boldsymbol{\varphi}$ referring to a vector of parameters of that density function (mean and variance), and all other terms are previously defined. The injury severity outcome probability is then a simple mixture of logits [32].

Estimation of the mixed logit model can be undertaken using simulated maximum likelihood approaches since it requires numerical integration of the logit formula over the distribution of the random, unobserved parameters [20]. Therefore, Halton sequence is typically used to draw the values of $\boldsymbol{\beta}_{i}$ because it has been reported to provide a more efficient distribution of draws for numerical integration than purely random draws [35-37]. Previous researches have shown that 200 Halton draws are usually sufficient for accurate parameter estimation $[22,37,38]$. In this study, normal distribution has been considered for the functional form of the parameter density functions.

Elasticities can be computed to assess the effects of variables on injury-outcome probabilities. However, since the variables in the injury severity context are generally indicator variable, calculating the regular elasticity is not possible due to the fact that probability is not differentiable with respect to a 0 or 1 indicator variable. Therefore, the marginal effects of indicator variables can be calculated through the change in probability when an indicator variable is switched from 0 to 1 or 1 to 0 . This approach yields a value called the direct pseudo-elasticity [33], and it is the percentage change in probability when an indicator variable is switched. For a 0 or 1 indicator variable, the direct pseudo-elasticity is computed as:

$$
E_{X_{k n}}^{P_{n i}}=\frac{P_{n i}\left[\text { given } X_{k n}=1\right]-P_{n i}\left[\text { given } X_{k n}=0\right]}{P_{n i}\left[\text { given } X_{k n}=0\right]},
$$

where $P_{n i}$ is defined by Eq. (3), $X_{k n}$ is the $k$ th independent variable associated with injury severity $i$ for individual $n$. In this study, the average pseudoelasticity of all individuals is calculated as a measure of the marginal effect of an indicator variable on the probability of a particular injury severity outcome.

\section{Data}

The database available for this study includes policereported crash data in Iran over a six-year period from January 1, 2006 to December 31, 2011. Weather data and literacy rate of the city in which collision happened were collected from Iran's Metrological Organization and Ministry of Education, respectively. Traffic data was obtained from Road Maintenance and Transportation Organization (RMTO) Website (www.rmto.ir). The collected data was used to investigate the effect of weather condition, driver socioeconomics, and collision characteristics on crash injury severities and provide insights for decision makers to apply right treatment for enhancing users' safety.

The initial database includes 8753 police-reported crashes that occurred on interprovincial routes in Iran. Of this data, 4354 resulted in no injuries, 3767 in minor injuries, and 632 in severe injuries. Table 1 provides descriptive statistics of the variables that found to be significant in model estimations.

\section{Model estimation results}

Tables 2 and 3 show the results of the mixed logit estimation and the corresponding direct and crosselasticities, respectively. In developing the model, parameters on the explanatory variables were tested, and if not found statistically different from zero at 0.90 level of confidence, they were restricted to zero. As seen in Table 2, all estimated parameters are statistically significant and the signs are plausible. Random parameters were statistically justified when they resulted in significant standard errors for their assumed estimation. Otherwise, they were kept fixed to be constant across the observations. The parameters found to be random for no injury crash function are indicator variables for "female drivers", "clear weather condition", and "separated bi-directional routes". Other random parameters are an indicator variable for "failing to maintain the distance from the vehicle in front/following too closely" defined for minor injury crash severity, and Average Annual Daily Traffic (AADT) defined for the severe crash severity.

The mixed logit model includes 26 statistically significant estimated parameters. The log-likelihood at zero (-7598.024) and at convergence (-4875.353) give a McFadden $\rho^{2}$ of 0.358 which is quite good considering the variance in crash-severity data. It needs to be mentioned that a simple multinomial logit model (with 26 estimated parameters) on the same data resulted in a log-likelihood at convergence of -5142.340 . Thus, the log-likelihood value of -4875.353 for the mixed logit model presented in this paper is a statistically significant improvement in model fit. Likelihood ratio test was used to compare the performance of mixed 
Table 1. Descriptive statistics of explanatory variables.

\begin{tabular}{|c|c|c|c|}
\hline Variable & Mean & Min & Max \\
\hline \multicolumn{4}{|l|}{ Unsafe driving behavior characteristics } \\
\hline $\begin{array}{l}\text { Failing to maintain the distance from the vehicle in front/ } \\
\text { following too closely ( } 1 \text { if the accident main cause is; } 0 \text { otherwise) }\end{array}$ & 0.078 & 0 & 1 \\
\hline Exceeding authorized speed limit ( 1 if the accident main cause is; 0 otherwise) & 0.123 & 0 & 1 \\
\hline $\begin{array}{l}\text { Disregarding traffic signs/traffic signals/road markings } \\
\text { ( } 1 \text { if the accident main cause is; } 0 \text { otherwise) }\end{array}$ & 0.045 & 0 & 1 \\
\hline Improper overtaking/passing ( 1 if the accident main cause is; 0 otherwise) & 0.034 & 0 & 1 \\
\hline Improper lane usage ( 1 if the accident main cause is; 0 otherwise) & 0.091 & 0 & 1 \\
\hline $\begin{array}{l}\text { Operating vehicle in erratic, reckless, careless, negligent, or aggressive } \\
\text { manner ( } 1 \text { if the accident main cause is; } 0 \text { otherwise) }\end{array}$ & 0.112 & 0 & 1 \\
\hline Inattention to the forward ( 1 if the accident main cause is; 0 otherwise) & 0.031 & 0 & 1 \\
\hline Not belted ( 1 if safety belt was not used; 0 otherwise) & 0.809 & 0 & 1 \\
\hline Literacy rate of the city where crash happened & 84.013 & 71.6 & 100 \\
\hline \multicolumn{4}{|l|}{ Driver characteristics } \\
\hline Female ( 1 if female driver; 0 otherwise) & 0.135 & 0 & 1 \\
\hline Young ( 1 if driver is younger than 30 years old; 0 otherwise) & 0.532 & 0 & 1 \\
\hline \multicolumn{4}{|l|}{ Crash characteristics } \\
\hline Multiple occupants ( 1 if vehicle had more than 1 occupant including driver; 0 otherwise) & 0.675 & 0 & 1 \\
\hline Vehicle-another vehicle collision ( 1 if collision type is vehicle-another vehicle; 0 otherwise) & 0.629 & 0 & 1 \\
\hline \multicolumn{4}{|l|}{ Vehicle characteristics } \\
\hline Passenger car ( 1 if driving a passenger car; 0 otherwise) & 0.489 & 0 & 1 \\
\hline \multicolumn{4}{|l|}{ Roadway characteristics } \\
\hline Average Annual Daily Traffic (AADT) (in thousands of vehicles per day) & 18.879 & 4.294 & 76.543 \\
\hline Separated bi-directional route ( 1 if collision on separated bi-directional route; 0 otherwise) & 0.401 & 0 & 1 \\
\hline Non-separated bi-directional route ( 1 if collision on separated bi-directional route; 0 otherwise) & 0.538 & 0 & 1 \\
\hline Freeway ( 1 if collision on freeway; 0 otherwise) & 0.459 & 0 & 1 \\
\hline \multicolumn{4}{|l|}{ Time characteristics } \\
\hline Daylight (1 if daylight; 0 otherwise) & 0.762 & 0 & 1 \\
\hline Night (1 if night; 0 otherwise) & 0.188 & 0 & 1 \\
\hline Holiday ( 1 if crash occurred during holiday; 0 otherwise) & 0.375 & 0 & 1 \\
\hline \multicolumn{4}{|l|}{ Weather characteristics } \\
\hline Clear weather ( 1 if clear weather, 0 otherwise) & 0.449 & 0 & 1 \\
\hline Rainy weather ( 1 if rainy weather; 0 otherwise) & 0.427 & 0 & 1 \\
\hline Snowy weather ( 1 if snowy weather; 0 otherwise) & 0.056 & 0 & 1 \\
\hline Dim visibility ( 1 if visibility is less than $2000 \mathrm{~m}$; 0 otherwise) & 0.242 & 0 & 1 \\
\hline
\end{tabular}

logit model and a multinomial logit model. Likelihood statistic of 266.987 and $26^{\circ}$ of freedom yielded 0.0001 level of significance; suggesting that the mixed logit is superior with over $99 \%$ level of confidence.

The significant variables for each severity outcome are discussed in the next section and are categorized as unsafe driving behavior characteristics, driver char- acteristics, crash characteristics, vehicle characteristics, roadway characteristics, time characteristics, and weather characteristics.

\subsection{Unsafe driving behavior characteristics}

With respect to the parameters found to be random, an indicator variable for failing to maintain the distance 
Table 2. Random parameters (mixed) logit model estimation results.

\begin{tabular}{|c|c|c|c|c|c|c|}
\hline \multirow{3}{*}{$\begin{array}{ll} & \text { Variable } \\
\text { Constant } & \\
\end{array}$} & \multicolumn{2}{|c|}{ No injury } & \multicolumn{2}{|c|}{ Minor injury } & \multicolumn{2}{|c|}{ Severe injury } \\
\hline & \multicolumn{6}{|c|}{ Est. par. $^{\text {a }}{ }^{\text {-st. }}{ }^{\text {b Est. par. } t \text {-st. Est. par. } t \text {-st. }}$} \\
\hline & - & - & 2.122 & 7.324 & - & - \\
\hline \multicolumn{7}{|l|}{ Unsafe driving behavior characteristics } \\
\hline $\begin{array}{l}\text { Failing to maintain the distance from the vehicle in front/following } \\
\text { too closely ( } 1 \text { if the accident main cause is; } 0 \text { otherwise) }\end{array}$ & - & - & -0.227 & -2.103 & - & - \\
\hline $\begin{array}{l}\text { Standard deviation of parameter (failing to maintain the } \\
\text { distancefrom the vehicle in front/following too closely) }\end{array}$ & - & - & 1.564 & 1.879 & - & - \\
\hline $\begin{array}{l}\text { Exceeding authorized speed limit ( } 1 \text { if the accident main cause is; } \\
0 \text { otherwise) }\end{array}$ & - & - & - & - & 0.345 & 3.769 \\
\hline $\begin{array}{l}\text { Disregarding traffic signs/traffic signals/ road markings ( } 1 \text { if the } \\
\text { accident main cause is; } 0 \text { otherwise) }\end{array}$ & -0.128 & -2.378 & - & - & - & - \\
\hline $\begin{array}{l}\text { Improper overtaking/passing ( } 1 \text { if the accident main cause is; } \\
0 \text { otherwise) }\end{array}$ & - & - & 0.211 & 1.785 & 0.563 & 2.312 \\
\hline Improper lane usage ( 1 if the accident main cause is; 0 otherwise) & - & - & 0.412 & 3.018 & - & - \\
\hline $\begin{array}{l}\text { Operating vehicle in erratic, reckless, careless, negligent, or aggressive } \\
\text { manner ( } 1 \text { if the accident main cause is; } 0 \text { otherwise) }\end{array}$ & - & - & - & - & 1.702 & 3.015 \\
\hline Inattention to the forward ( 1 if the accident main cause is; 0 otherwise) & 0.711 & 2.711 & - & - & - & - \\
\hline Not belted ( 1 if safety belt was not used; 0 otherwise) & - & - & -0.521 & -2.947 & - & - \\
\hline Literacy rate of the city where crash happened & - & - & - & - & -1.070 & -3.568 \\
\hline \multicolumn{7}{|l|}{ Driver characteristics } \\
\hline Female ( 1 if female driver; 0 otherwise) & 0.056 & 0.561 & - & - & - & - \\
\hline Standard deviation of parameter (female) & 3.241 & 3.567 & - & - & - & - \\
\hline $\begin{array}{l}\text { Young ( } 1 \text { if driver is younger than } 30 \\
\text { years old; } 0 \text { otherwise) }\end{array}$ & - & - & -0.521 & -2.765 & - & - \\
\hline \multicolumn{7}{|l|}{ Crash characteristics } \\
\hline $\begin{array}{l}\text { Multiple occupants ( } 1 \text { if vehicle had more } \\
\text { than } 1 \text { occupant including driver; } 0 \text { otherwise) }\end{array}$ & - & - & 0.508 & 1.802 & - & - \\
\hline $\begin{array}{l}\text { Vehicle-another vehicle collision ( } 1 \text { if collision } \\
\text { type is vehicle-another vehicle; } 0 \text { otherwise) }\end{array}$ & - & - & -0.657 & -1.865 & - & - \\
\hline
\end{tabular}

\section{Vehicle characteristics}

Passenger car ( 1 if driving a passenger

car; 0 otherwise)

\section{Roadway characteristics}

Average annual daily traffic (AADT) (in thousands of vehicles per day)

Standard deviation of parameter (AADT)

Separated bi-directional route ( 1 if collision on separated bi-directional route; 0 otherwise)

Standard deviation of parameter (separated bi-directional route) $\quad \begin{array}{lll}0.801 & 1.671\end{array}$

Non-separated bi-directional route ( 1 if collision on separated bi-directional route; 0 otherwise)

$2.055 \quad 3.211$

Freeway ( 1 if collision on freeway; 0 otherwise)

${ }^{\mathrm{a}}$ Est. par.: Estimated parameter; ${ }^{\mathrm{b}} t$-st.: $t$-statistic. 
Table 2. Random parameters (mixed) logit model estimation results (continued).

\begin{tabular}{|c|c|c|c|c|c|c|}
\hline \multirow{2}{*}{ Variable } & \multicolumn{2}{|c|}{ No injury } & \multicolumn{2}{|c|}{ Minor injury } & \multicolumn{2}{|c|}{ Severe injury } \\
\hline & Est. par. ${ }^{\mathrm{a}}$ & $t$-st. ${ }^{\mathrm{b}}$ & Est. par. & $t$-st. & Est. par. & $t$-st. \\
\hline \multicolumn{7}{|l|}{ Time characteristics } \\
\hline Daylight ( 1 if daylight; 0 otherwise) & 1.076 & 2.793 & - & - & - & - \\
\hline Night (1 if night; 0 otherwise) & & & & & 0.671 & 3.042 \\
\hline Holiday ( 1 if crash occurred during holiday; 0 otherwise) & - & - & - & - & 0.807 & 4.326 \\
\hline \multicolumn{7}{|l|}{ Weather characteristics } \\
\hline Clear weather ( 1 if clear weather, 0 otherwise) & 1.205 & 1.678 & - & - & - & - \\
\hline Standard deviation of parameter (clear weather) & 1.561 & 1.835 & - & - & - & - \\
\hline Rainy weather ( 1 if rainy weather; 0 otherwise) & 1.002 & 3.276 & - & - & - & - \\
\hline Snowy weather ( 1 if snowy weather; 0 otherwise) & - & - & -0.359 & -1.673 & - & - \\
\hline Dim visibility ( 1 if visibility is less than $2000 \mathrm{~m}$; 0 otherwise) & -0.643 & -2.164 & - & - & - & - \\
\hline
\end{tabular}

Number of observations: 8753

Log-likelihood at zero: -7598.024

Log-likelihood at convergence: -4875.353

McFadden $\rho^{2}: 0.358$

a Est. par.: Estimated parameter; ${ }^{\mathrm{b}} t$-st.: $t$-statistic.

from the vehicle in front/following too closely, defined for minor injury severity level, results in a parameter that is normally distributed with a mean -0.227 and standard deviation 1.564. This implies that $55.77 \%$ of the distribution is less than zero and the remaining $44.33 \%$ is more than zero. In other words, $55.77 \%$ of crashes, in which the aforementioned parameter is the main cause of accident, result in an increase in minor injury crashes (consequently, decreasing the likelihood of no injury and severe injury crashes) and for $44.33 \%$ of the crashes result in a decrease in minor injury crashes. This variable may capture the complexity of collision nature where the use of seat belt, airbag, speed of the car, etc. plays significant roles. For example, even though, in Iran, the number of cars equipped with airbag is increasing, still many cars are not equipped with air bag.

Intuitively, exceeding the authorized speed limit is one of the main causes of crash in many countries. An indicator variable for exceeding authorized speed limit was defined for severe injury function, and it was found to increase the likelihood of this crash severity level. Nonetheless, the variable was found to be a fixed parameter. The pseudo-elasticity values show that exceeding the authorized speed limit increases the probability of severe injury crash by $39.8 \%$ and decreases the probabilities of no injury and minor injury crashes by $-29.7 \%$ and $-18 \%$, respectively. Among the other factors, this variable seems to have the potential to capture the extent of impact of collision, that is, vehicles (especially large ones) travelling at higher speeds are less able to slow down and reduce the force of impact. Inattention to the forward when defined as an indicator variable for no injury function was found to increase the likelihood of this crash severity. The corresponding pseudo-elasticity values show that crashes in which inattention to forward is the main cause of the collision have a $8.7 \%$ more probability to be ended as a no injury crash.

As can be seen from the estimated model, disregarding traffic signs and signals and improper overtaking/passing would increase the likelihood of most severe injuries. With regard to overtaking/passing, this variable was defined for both minor and severe injury functions. Improper lane usage was defined as an indicator variable for minor injury severity level and found to increase the likelihood of minor injuries (i.e., decreasing the likelihood of no injury and severe injury). Operating vehicle in erratic, reckless, careless, negligent, or aggressive manner is another indicator variable that was defined for severe injury function. This variable was found to increase the likelihood of severe injury function.

Safety belt usage indicator variable ( 1 if driver does not wear seat belt, 0 otherwise) was defined for severe injury function and kept fixed across the observations. It was found that those drivers not wearing safety belts increase the likelihood of severe injury function and decrease the likelihood of other functions. The pseudo-elasticity values show that drivers without safety belt have a $15.2 \%$ more probability to get involved in severe injury crashes. This result is in line with the findings of previous studies [21] and shows the effectiveness of seat belt usage as a vehicle safety device.

The illiteracy rate (which is a number between 0 
Table 3. Estimated pseudo-elasticity values of the mixed logit model for crash severity outcomes, in percent (variables are defined for three injury outcomes: No Injury [NI], Minor Injury [MI], and Severe Injury [SI]).

\begin{tabular}{|c|c|c|c|}
\hline Variable & $\begin{array}{l}\text { No } \\
\text { injury }\end{array}$ & $\begin{array}{l}\text { Minor } \\
\text { injury }\end{array}$ & $\begin{array}{l}\text { Severe } \\
\text { injury }\end{array}$ \\
\hline \multicolumn{4}{|l|}{ Unsafe driving behavior characteristics } \\
\hline $\begin{array}{l}\text { Failing to maintain the distance from the vehicle in front/following too closely } \\
\text { ( } 1 \text { if the accident main cause is; } 0 \text { otherwise) [MI] }\end{array}$ & 15.3 & -11.4 & 13.2 \\
\hline Exceeding authorized speed limit ( 1 if the accident main cause is; 0 otherwise) [SI] & -29.7 & -18.0 & 39.8 \\
\hline $\begin{array}{l}\text { Disregarding traffic signs/traffic signals/road markings } \\
\text { (1 if the accident main cause is; } 0 \text { otherwise) }[\mathrm{NI}]\end{array}$ & -10.5 & 21.2 & 38.9 \\
\hline Improper overtaking/passing ( 1 if the accident main cause is; 0 otherwise) [MI] & -8.4 & 19.6 & -14.4 \\
\hline Improper overtaking/passing ( 1 if the accident main cause is; 0 otherwise) [SI] & -7.3 & -4.6 & 9.2 \\
\hline Improper lane usage ( 1 if the accident main cause is; 0 otherwise) [MI] & -3.4 & 5.6 & -7.4 \\
\hline $\begin{array}{l}\text { Operating vehicle in erratic, reckless, careless, negligent, or aggressive } \\
\text { manner ( } 1 \text { if the accident main cause is; } 0 \text { otherwise) }[\mathrm{SI}]\end{array}$ & -13.37 & -7.9 & 18.5 \\
\hline Inattention to the forward ( 1 if the accident main cause is; 0 otherwise) [NI] & 8.7 & -6.3 & -3.4 \\
\hline Not belted ( 1 if safety belt was not used; 0 otherwise) [MI] & 8.3 & -7.6 & 15.2 \\
\hline Literacy rate of the city where crash happened [SI] & 13.4 & 8.2 & -35.7 \\
\hline \multicolumn{4}{|l|}{ Driver characteristics } \\
\hline Female ( 1 if female driver; 0 otherwise) $[\mathrm{NI}]$ & 30.95 & -2.9 & -2.8 \\
\hline Young ( 1 if driver is younger than 30 years old; 0 otherwise) & 12.4 & -7.9 & 16.3 \\
\hline \multicolumn{4}{|l|}{ Crash characteristics } \\
\hline $\begin{array}{l}\text { Multiple occupants ( } 1 \text { if vehicle had more than } 1 \text { occupant including driver; } \\
0 \text { otherwise) }[\mathrm{MI}]\end{array}$ & -2.4 & 5.6 & -25.4 \\
\hline $\begin{array}{l}\text { Vehicle-another vehicle collision ( } 1 \text { if collision type is vehicle-another vehicle; } \\
0 \text { otherwise) [MI] }\end{array}$ & 18.2 & -7.8 & 17.2 \\
\hline \multicolumn{4}{|l|}{ Vehicle characteristics } \\
\hline Passenger car ( 1 if driving a passenger car; 0 otherwise) [SI] & -9.5 & -20.4 & 38.9 \\
\hline \multicolumn{4}{|l|}{ Roadway characteristics } \\
\hline Average Annual Daily Traffic (AADT) (in thousands of vehicles per day) [SI] & -2.4 & -5.6 & 25.4 \\
\hline $\begin{array}{l}\text { Separated bi-directional route ( } 1 \text { if collision on separated bi-directional route; } \\
0 \text { otherwise) }[\mathrm{NI}]\end{array}$ & 15.5 & -4.7 & -6.7 \\
\hline $\begin{array}{l}\text { Non-separated bi-directional route ( } 1 \text { if collision on separated bi-directional route; } \\
0 \text { otherwise) }[\mathrm{SI}]\end{array}$ & -5.7 & -3.6 & 13.3 \\
\hline Freeway ( 1 if collision on freeway; 0 otherwise) [SI] & 5.1 & 3.4 & -10.3 \\
\hline \multicolumn{4}{|l|}{ Time characteristics } \\
\hline Daylight (1 if daylight; 0 otherwise) $[\mathrm{NI}]$ & 68.3 & -5.8 & -8.6 \\
\hline Night (1 if night; 0 otherwise) [SI] & -9.5 & -5.6 & 10.1 \\
\hline Holiday ( 1 if crash occurred during holiday; 0 otherwise) [SI] & -14.0 & -9.3 & 28.7 \\
\hline \multicolumn{4}{|l|}{ Weather characteristics } \\
\hline Clear weather ( 1 if clear weather, 0 otherwise) $[\mathrm{NI}]$ & 99.5 & -4.2 & -5.4 \\
\hline Rainy weather ( 1 if rainy weather; 0 otherwise) [NI] & 37.6 & -5.2 & -8.18 \\
\hline Snowy weather ( 1 if snowy weather; 0 otherwise) [MI] & 1.8 & -1.1 & 5.4 \\
\hline Dim visibility ( 1 if visibility is less than $2000 \mathrm{~m}$; 0 otherwise) [NI] & -30.8 & 1.6 & 2.4 \\
\hline
\end{tabular}


to 100 indicating the percentage of literate people) was included in the model by taking the average illiteracy rate of the city in which the accident was happened. This variable was defined for severe injury function. Here, we found that increasing the illiteracy rate results in less severe accidents. Among the other factors, this might capture the behavior of drivers who disregard traffic rules or act aggressively. Moreover, unsafe and risky behavior, less use of seat belts, no use of child restraint seats would increase the likelihood of being involved in crashes. A more detailed approach where measures include the literacy rate of the driver could increase the accuracy of the model.

\subsection{Driver characteristics}

Regarding the parameters found to be random, an indicator variable for female drivers ( 1 if driver is female, 0 otherwise), which is defined for no injury severity level, results in a parameter that is normally distributed with a mean 0.056 and standard deviation 3.241. Given these distributional parameters, $49.31 \%$ of the distribution is less than zero and $51.69 \%$ is greater than zero. This implies that slightly more than half of the female drivers result in an increase in no injury accidents (consequently, decreasing the likelihood of more severe accidents) and slightly less than half result in an decrease in no injury (consequently, decreasing the likelihood of more severe accidents). Injury severity differences between male and female drivers in road accidents have also been discussed in the previous studies [13,21]. An explanation for this observation is that probably females are more cautious and safer drivers, which reduces their injury severities $[21,22,39]$. However, compared to males, females drive less and with it comes less experience $[21,22,40]$ leading to less flexibility in decisions making at complex situations. Ulfarsson and Mannering (2004) reported that behavioral and physiological differences between male and female drivers are the cause of dramatic male-female differences in the determinants of injury severities across vehicle types. The heterogeneity of gender effect can be observed from the highly statistically significant standard deviation estimate on the "male" variable, which has been discussed in a number of previous studies [41-43].

Young driver indicator variable ( 1 if driver is younger than 30 years old, 0 otherwise) was defined for minor injury severity level and kept fixed across the observations. This variable was found to decrease the likelihood of minor injury and increase the probability of other severity levels. The pseudo-elasticity values show that a young driver has $16.3 \%$ and $12.4 \%$ more probability of getting involved in severe injury or minor injury severity levels, respectively. Increasing the likelihood of severe injury might be due to the fact that some younger drivers tend to disregard traf- fic rules or act aggressively as reported in previous studies $[1,21,44]$. Increased likelihood of no injury severity for this variable might be due to the faster and evasive action of young drivers as a crash starts to develop. This fact leads to the experience of less severe crashes. Although age variables have been found to have substantial heterogeneity [21], the results of the current study did not show any significant heterogeneity; the standard error of the distribution of these parameters, when allowed to be random, was statistically insignificant.

\subsection{Crash characteristics}

Multiple occupants (1 if vehicle had more than 1 occupant including driver; 0 otherwise) was defined for minor injury severity level and found to increase the likelihood of other severity levels. The pseudoelasticity value for this variable for no injury and severe injury levels are $-2.4 \%$ and $-25.4 \%$, respectively. This parameter may capture the complexity of the behavior and number of occupants. For example, it is reasonable to assume that when parents are in the car, young drivers try to follow the traffic rules. However, while the other occupants are young people, the probability of disregarding the traffic rules increases.

An indicator variable of vehicle-another vehicle collision ( 1 if collision involves another vehicle, 0 otherwise) was found to be significant in the likelihood of minor injury severity level. Its estimated parameter was fixed across the observation (the standard error of the distribution of this parameter, when allowed to be random was statistically insignificant). The pseudo-elasticity value for this variable in case of minor injury function was computed as $-7.8 \%$, suggesting that vehicle-another vehicle collision has a $7.8 \%$ less probability of leading to minor injury severity. This variable may capture the complexity of collision nature. For example, it is reasonable to think of a less severe crash in case of a collision with immobile object. It is also intuitive to think about more severe crashes in case of overturned vehicle.

\subsection{Vehicle characteristics}

In terms of vehicle characteristics, an indicator variable of passenger cars ( 1 if the involved car in the accident is passenger car, 0 otherwise) was defined for severe injury function. Its estimated parameter was fixed across the observations. This parameter increases the likelihood of most severe crashes. This might be due to the fact that passenger cars provide less protection for their occupants compared to larger vehicles. These effects could be attributable to the body size and mass of different vehicle types. In addition, in Iran, many passenger cars do not meet safety standards. The pseudo-elasticity value for this parameter indicates that passenger cars have a $38.9 \%$ more probability of 
leading to severe injuries. In a study conducted by Khattak [10], the injury severity of multivehicle rearend crashes was investigated, and it was found that passenger cars are more vulnerable to severe crashes in rear-end collisions.

\subsection{Roadway characteristics}

The Annual Average Daily Traffic (AADT) was defined for severe injury level and resulted in random parameter that is normally distributed with mean -0.112 and standard deviation 0.103. Given this distributional parameters, $11.81 \%$ is greater than zero and $88.19 \%$ is less than zero. This implies that for $11.81 \%$ of the observations, increases in the AADT would increase the likelihood of severe injuries (i.e., the likelihood of no injury and minor injury would decrease), whereas for $88.19 \%$ of the observations, increases in the AADT would lead to decrease in the likelihood of severe injuries. The finding for this variable is likely picking up a complex interaction among driver behavior, traffic volume, and accident severity. Since the interprovincial routes are scattered throughout the country, the effect of the AADT on increasing the probability of severe crashes on some routes and decreasing it on others may be capturing, among the other factors, the response and adaption of local drivers to various levels of traffic volume.

Separated bi-directional route was defined for no injury crash severity level and resulted in normal distributed variable with mean 0.739 and standard deviation 0.801 . For about $82.19 \%$ of the crashes, this parameter is found to increase the likelihood of no injury crashes. This might be due to the fact that separated bi-directional route provides better visual aids for drivers. The pseudo-elasticity value for this parameter shows that separated bi-directional routes on average have a $15.5 \%$ more probability of having no injury crash severity. Non-separated bi-directional route was defined for severe injury level, and it was found to increase the likelihood of severe injury.

Freeway indicator variable was defined for severe injury function. It was observed that this parameter decreases the likelihood of severe injury crashes and, in turn, increases the probability of no injury and minor injury crashes. The calculated pseudo-elasticity value for this variable indicates that freeways have a $10.3 \%$ less probability of leading to severe injury (i.e., increases the likelihood of no injury and minor injury levels by $5.1 \%$ and $3.4 \%$, respectively).

\subsection{Time characteristics}

An indicator variable of the day-time (1 if collision occurred during the day, 0 otherwise), was defined for no injury severity function and kept fixed across the observations. It should be mentioned that daytime in this study is the time between sunrise to sunset. Partitioning of the day into three time periods, morning peak, evening peak, and off-peak, did not show any statistically significant difference in injury severity. The positive sign of this variable shows that this variable increases the likelihood of no injury function and decreases the likelihood of minor and severe injuries. Driving during the day-time increases the visibility as well as driver's attention to the road. The pseudo-elasticity value of this parameter implies that day-time crash has a $68.3 \%$ more probability of leading to no injury.

Night indicator variable ( 1 if collision occurred during the night, 0 otherwise) was defined for severe injury function and kept fixed across the observations. The positive sign of this variable implies that it increases the likelihood of severe injuries and decreases the likelihood of no and minor injuries. This is consistent with those observed for day-time period and is likely a consequence of less visibility at night-time, which can lead to slower reaction times and higher impacts at the time of the crash. The pseudo-elasticity value for this parameter shows that night-time crash has a $10.1 \%$ more probability of causing severe injury.

National holidays are associated with an increase in the likelihood of the severe injury crashes which is in line with the findings of Kim et al. (2013). This could be due to the drivers' behavior who act differently during holidays compared to other days. This finding indicates that additional safety rules might be required for holidays.

\subsection{Weather characteristics}

Turning to weather variables, an indicator variable for clear weather condition was defined for no injury function. This parameter was found to be normally distributed with mean 1.205 and standard deviation 1.561 , which results in $22 \%$ of the distribution less than zero, and $78 \%$ of the distribution greater than zero. This shows that for a small proportion of crashes, clear weather condition increases the likelihood of no injury function (i.e., decreases the likelihood of minor or severe injuries), while for the majority of drivers (perhaps those who feel safer and more confident and drive without paying enough attention to the road), this likelihood tends to decrease.

Rainy weather condition was also found to increase the probability of no injury function. This is reasonable to expect that rain creates hazardous conditions such as decreasing the friction between pavement surface and tire and increasing the breaking distance. In addition, rain reduces driver perception in several ways and is especially debilitating at night. Furthermore, rain has influence on visibility through its action on headlamps, windshields, the road itself, and road markings. An object becomes observable when light from a source such as the sun, streetlamps, or 
headlights reflects from the object back to the eye. Rain interferes with this process in several ways such as filtering away some of the lights and reducing the contrast. The pseudo-elasticity value of this parameter implies that rainy weather has a $37.6 \%$ more probability of leading to no injury crash. The significance of this variable indicates that drivers compensate for rainy conditions by reducing their speed or driving more carefully.

Snowy weather condition was found to decrease the probability of minor injury function. Similar to rain, snow creates hazardous conditions such as decreasing the friction between pavement surface and tire, increasing the breaking distance and making it difficult for drivers to slow down to reduce impact severity. However, it should be considered that drivers typically tend to use lower speeds in snowy weather. Therefore, this competing effect of snow increases the likelihood of least and most severe crashes. However, the pseudoelasticity values of $1.8 \%$ and $5.4 \%$ that were found for no injury and sever injury functions, respectively, suggest that the effect of snow in increasing these severity levels is not significant.

Less visibility ( 1 if visibility is less than $2000 \mathrm{~m}, 0$ otherwise) was found to be a fixed parameter that significantly reduced the likelihood of no injury function (i.e., increased the likelihood of more severe crashes). Less visibility might reduce the color contrast, which can cause drivers to make themselves more vulnerable by not being adequately visible to another oncoming driver or obstacle. Moreover, less visibility can also lead to a less effective response by the driver, i.e., breaking or avoidance maneuvers, as suggested by Kim et al. and Behnood and Mannering [44-45].

\section{Summary and conclusion}

This paper provides a demonstration of a mixed logit model as a methodological approach to gain new insights into the ways that various factors significantly influence accident severities. The random parameter logit model is an important approach since it allows to capture the heterogeneity through the use of random parameters. In addition, mixed logit model allows explanatory variables to affect the mean of the distribution of the random parameters.

Using the 6 years of vehicle accident data in Iran, the estimation results provide some interesting findings, particularly those related to unsafe driving behavior. The results showed random effects of female drivers, separated bi-directional route, and clear weather condition for no injury severity function, following too closely for minor injury function, and average annual daily traffic for severe injury function.

The findings of this study demonstrate the application of the mixed logit model; however, additional study is required to further explore the unobserved human factors affecting injury severity such as the driver's health and possible medical condition or driver distraction due to internal and external factors. Such currently unobserved factors could be important for a more detailed and accurate evaluation heterogeneity. A more detailed approach, where measures include route geometry configuration, traffic control device, and roadway surface condition, can lead to a more comprehensive model.

\section{References}

1. Lozano, R., Naghavi, M. Foreman, K., et al. "Global and regional mortality from 235 causes of death for 20 age groups in 1990 and 2010: a systematic analysis for the Global Burden of Disease Study 2010", Lancet, 380, pp. 2095-2028 (2012).

2. Toroyan, T., Global Status Report on Road Safety: Supporting a Decade of Action, World Health Organization, Geneva, Switzerland, p. 318 (2013).

3. Rasouli, M.R. Nouri, M., Zarei, M-R., Saadat, S. and Rahimi-Movaghar, V. "Comparison of road traffic fatalities and injuries in Iran with other countries", Chin. J. Traumatol., 11, pp. 131-134 (2008).

4. Vereeck, L. and Vrolix, K. "The social willingness to comply with the law: The effect of social attitudes on traffic fatalities", Int. Rev. Law. Econ., 27, pp. 385-408 (2007).

5. Fridstr $\phi \mathrm{m}$, L. and Ingebrigtsen, S. "An aggregate accident model based on pooled, regional time-series data", Accid. Anal. Prev., 23, pp. 363-378 (1991).

6. Melinder, K. "Socio-cultural characteristics of high versus low risk societies regarding road traffic safety", Saf. Sci., 45, pp. 397-414 (2007).

7. Çelik, A.K. and Oktay, E. "A multinomial logit analysis of risk factors influencing road traffic injury severities in the Erzurum and Kars provinces of Turkey", Accid. Anal. Prev., 72, pp. 66-77 (2014).

8. Shinar, D., Schechtman, E. and Compton, R. "Selfreports of safe driving behaviors in relationship to sex, age, education and income in the US adult driving population", Accid. Anal. Prev., 33, pp. 111116 (2001).

9. Mannering, F.L. and Bhat, C.R. "Analytic methods in accident research: Methodological frontier and future directions", Anal. Methods. Accid. Res, 1, pp. 1-22 (2014).

10. Khattak, A.J. "Injury severity in multivehicle rear-end crashes", Transp. Res. Rec. J. Transp. Res. Board., 1746, pp. 59-68 (2007).

11. Kockelman, K.M. and Kweon, Y-J. "Driver injury severity: an application of ordered probit models", Accid. Anal. Prev., 34, pp. 313-321 (2002).

12. Abdel-Aty, M. "Analysis of driver injury severity levels at multiple locations using ordered probit models", $J$. Safety. Res., 34, pp. 597-603 (2003). 
13. Ulfarsson, G.F. and Mannering, F.L. "Differences in male and female injury severities in sport-utility vehicle, minivan, pickup and passenger car accidents", Accid. Anal. Prev., 36, pp. 135-47 (2004).

14. Yamamoto, T. and Shankar, V.N. "Bivariate orderedresponse probit model of driver's and passenger's injury severities in collisions with fixed objects", Accid. Anal. Prev., 36, pp. 869-876 (2004).

15. Khorashadi, A., Niemeier, D., Shankar, V. and Mannering, F.L. "Differences in rural and urban driverinjury severities in accidents involving large-trucks: an exploratory analysis", Accid. Anal. Prev., 37, pp. 910921 (2005)

16. Lee, C. and Abdel-Aty, M. "Comprehensive analysis of vehicle-pedestrian crashes at intersections in Florida", Accid. Anal. Prev., 37, pp. 775-786 (2005).

17. Eluru, N., Bhat, C.R. and Hensher, D.A. "A mixed generalized ordered response model for examining pedestrian and bicyclist injury severity level in traffic crashes", Accid. Anal. Prev., 40, pp. 1033-1054 (2008).

18. Savolainen, P. and Mannering, F.L. "Probabilistic models of motorcyclists' injury severities in single- and multi-vehicle crashes", Accid. Anal. Prev., 39, pp. 955963 (2007).

19. Quddus, M.A., Wang, C. and Ison, S.G. "Road traffic congestion and crash severity: Econometric analysis using ordered response models", J. Transp. Eng., 136, pp. 424-435 (2010).

20. Milton, J.C., Shankar, V.N. and Mannering, F.L. "Highway accident severities and the mixed logit model: an exploratory empirical analysis", Accid. Anal. Prev., 40, pp. 260-266 (2008).

21. Behnood, A., Roshandeh, A.M. and Mannering, F.L. "Latent class analysis of the effects of age, gender, and alcohol consumption on driver-injury severities", Anal. Methods. Accid. Res., 3-4, pp. 56-92 (2014).

22. Behnood, A. and Mannering, F.L. "The temporal stability of factors affecting driver-injury severities in single-vehicle crashes: Some empirical evidence", Anal. Methods. Accid. Res., 8, pp. 7-32 (2015).

23. Roshandeh, A.M., Zhou, B. and Behnood, A. "Comparison of contributing factors in hit-and-run crashes with distracted and non-distracted drivers", Transp. Res. Part. F: Traffic Psychol. Behav., 38, pp. 2-28 (2016).

24. Chang, L.-Y. and Wang, H.-W. "Analysis of traffic injury severity: An application of non-parametric classification tree techniques", Accid. Anal. Prev., 38, pp. 1019-1027 (2006).

25. Abdelwahab, H. and Abdel-Aty, M. "Development of artificial neural network models to predict driver injury severity in traffic accidents at signalized intersections", Transp. Res. Rec. J. Transp. Res. Board., 1746, pp. 6-13 (2001).

26. Abdelwahab, H. and Abdel-Aty, M. "Artificial neural networks and logit models for traffic safety analysis of toll plazas", Transp. Res. Rec., 1784, pp. 115-125 (2002).
27. Li, Z., Liu, P., Wang, W. and Xu, C. "Using support vector machine models for crash injury severity analysis", Accid. Anal. Prev., 45, pp. 478-486 (2012).

28. Savolainen, P.T., Mannering, F.L., Lord, D. and Quddus, M.A. "The statistical analysis of highway crash-injury severities: a review and assessment of methodological alternatives", Accid. Anal. Prev., 43, pp. 1666-1676 (2011).

29. Kim, J-K., Ulfarsson, G.F., Shankar, V.N. and Mannering, F.L. "A note on modeling pedestrian-injury severity in motor-vehicle crashes with the mixed logit model", Accid. Anal. Prev., 42, pp. 1751-1758 (2010).

30. Mcfadden, D., Econometric Models for Probabilistic Choice. Structural Analysis of Discrete Data Using Econometric Applicatios, Cambridge, MA: MIT Press (1981).

31. Mcfadden, D. and Train, K. "Mixed MNL models for discrete response", J. Appl. Econom., 15, pp. 447-470 (2000).

32. Train, K., Discrete Choice Methods with Simulation, 2nd Ed., Cambridge, UK, Cambridge University Press (2009).

33. Washington, S.P., Karlaftis, M.G. and Mannering, F.L., Statistical and Econometric Methods for Transportation Data Analysis, 2nd Ed., Chapman and Hall/CRC, Boca Raton, FL, Taylor \& Francis (2011).

34. Anastasopoulos, P. and Mannering, F.L. "An empirical assessment of fixed and random parameter logit models using crash- and non-crash-specific injury data", Accid. Anal. Prev., 43, pp. 1140-1147 (2011).

35. Geweke, J., Keane, M. and Runkle, D. "Alternative computational approaches to inference in the multinomial probit model", Rev. Econ. Stat., 76, pp. 609-632 (1994).

36. McFadden, D. and Ruud, P.A. "Estimation by simulation", Rev. Econ. Stat., 76, pp. 591-608 (1994).

37. Bhat, C.R. "Simulation estimation of mixed discrete choice models using randomized and scrambled Halton sequences", Transp. Res. Part. B: Methodol., 37, pp. 837-855 (2003).

38. Anastasopoulos, P.C. and Mannering, F.L. "A note on modeling vehicle accident frequencies with randomparameters count models", Accid. Anal. Prev., 41, pp. 153-159 (2009).

39. Yagil, D. "Gender and age-related differences in attitudes toward traffic laws and traffic violations", Transp. Res. Part. F: Traffic Psychol. Behav., 1, pp. 123-135 (1998).

40. Harre, N., Field, J. and Kirkwood, B. "Gender differences and areas of common concern in the driving behaviors and attitudes of adolescents", Safety. Res., 27, pp. 163-173 (1996).

41. Paleti, R., Eluru, N. and Bhat, C.R. "Examining the influence of aggressive driving behavior on driver injury severity in traffic crashes", Accid. Anal. Prev., 42, pp. 1839-1854 (2010). 
42. Abay, K.A., Paleti, R. and Bhat, C.R. "The joint analysis of injury severity of drivers in two-vehicle crashes accommodating seat belt use endogeneity", Transp. Res. Part. B: Methodol., 50, pp. 74-89 (2013).

43. Eluru, N. and Bhat, C.R. "A joint econometric analysis of seat belt use and crash-related injury severity", Accid. Anal. Prev., 39, pp. 1037-1049 (2007).

44. Kim, J.-K., Ulfarsson, G.F., Kim, S. and Shankar, V.N. "Driver-injury severity in single-vehicle crashes in California: A mixed logit analysis of heterogeneity due to age and gender", Accid. Anal. Prev., 50, pp. 1073-1081 (2013).

45. Behnood, A. and Mannering, F. "An empirical assessment of the effects of economic recessions on pedestrian-injury crashes using mixed and latent-class models", Anal. Methods. Accid. Res., 12, pp.1-17 (2016).

\section{Biographies}

Ali Behnood received the BS and MSc degrees in Civil Engineering from Iran University of Science and Technology. In 2016, he received his $\mathrm{PhD}$ degree form Purdue university. $\mathrm{He}$ is currently a Post-Doctoral Reseacrh Assistant at Purdue University. As a multidisciplinary scholar, he works in interdisciplinary and transdisciplinary ways. His current research interests include transportation economics and safety, pavement engineering, concrete durability, asphalt binders and mixtures, and artificial intelligence.

Mahsa Modiri-Gharehveran received the BS and MSc degrees in Civil Engineering from Tabriz University and Iran University of Science and Technology, respectively. She is currently a $\mathrm{PhD}$ student in Civil Engineering in Purdue University. Her current research interests include transportation safety, artificial intelligence, climate change, water quality, photochemistry reaction mechanisms, and aquatic chemistry.

Arash Moradkhani Roshandeh is currently an Engineer at Traffic Control Center of the City of Alpharetta, GA, working on various transportationrelated projects jointly with Georgia Department Of Transportation (GDOT). Prior his current position, he was a post-doctoral research associate in the area of Transportation and Infrastructure Systems Engineering in Purdue University, working on multiple projects from Indiana DOT. He did his PhD of Civil Engineering at Illinois Institute of Technology, Chicago. During his $\mathrm{PhD}$, he worked on projects sponsored by Federal Highway Administration (FHWA) and Illinois Tollway Authority. He completed his Masters and Bachelor degrees both in Civil Engineering in University Technology of Malaysia and University of Mazandaran, Iran, respectively. 